\title{
Spatial magnetic properties subject to lone pair and $\pi$ electron delocalization in benzenoid and quinoid structures. Are quinoid tautomers really nonaromatic?
}

\author{
Erich Kleinpeter* and Andreas Koch \\ Universität Potsdam, Institut für Chemie, Karl-Liebknecht-Str. 24-25, D-14476 Potsdam(Golm), \\ Germany \\ E-mail: ekleinp@uni-potsdam.de
}

Dedicated to Prof. Ferenc Fülöp on the occasion of his $60^{\text {th }}$ birthday

\begin{abstract}
The spatial magnetic properties, through-space NMR shieldings (TSNMRS), of benzenoid and quinoid tautomeric structures such as benzodifurantrione and phenazine-type molecules have been calculated using the GIAO perturbation method employing the nucleus independent chemical shift (NICS) concept of Paul von Ragué Schleyer and visualized as iso-chemicalshielding surfaces (ICSS) of various size and direction. The TSNMRS values were employed to quantify and visualize the partial aromaticity of the studied compounds. In the case of the surprisingly more stable quinoid tautomers, the aromaticity-synonymous with stability due to the conjugation of $\pi$ electrons and lone pairs-was not found to be particularly reduced.
\end{abstract}

Keywords: Through-space NMR shieldings (TSNMRS), GIAO, NICS, benzenoid structures, quinoid structures, aromaticity

\section{Introduction}

The shielding at or above the center of aromatic ring systems and realized by the concept of nucleus independent chemical shielding (NICS), ${ }^{1}$ is a parameter that can be used to characterize the aromaticity of organic compounds. NICS values calculated for a grid system surrounding the molecules can also be used to locate the diatropic and paratropic regions of the molecules involved. $^{2-8}$ Moreover, through-space NMR shieldings (TSNMRS) have been visualized ${ }^{3}$ as isochemical-shielding surfaces (ICSS) and employed to quantify the anisotropic effects of functional groups, to determine the stereochemisty of nuclei proximal to functional groups, ${ }^{3,9-14}$ to assess the conformational state when the underlying dynamic process is fast on the NMR timescale, ${ }^{15}$ to separate the anisotropic effect of the $\mathrm{C}=\mathrm{C}$ double bond from the influence of steric 
hindrance on the same protons, ${ }^{16,17}$ and to visualize and quantify planar $^{18}$ and spherical (anti)aromaticity. ${ }^{19-21}$

Recently, using our approach,, 3 we found the TSNMRS methodology to be a viable alternative for the identification of benzenoid/quinoid structures if the ${ }^{1} \mathrm{H}$ NMR spectra are too complex or if X-ray structures were unavailable. ${ }^{22}$ In another study, ${ }^{23}$ we extended our examination to keto-enol tautomers (with benzenoid, quinoid, antiaromatic or pseudoaromatic substructures) and push-pull structures (which can exist as zwitterionic forms with pseudoaromatic substructures) in order to identify the size of the partial aromaticity. Usually, aromatic tautomers in comparison to their corresponding quinoid tautomers are considered to be much more stable. However, there are a very few cases where quinoid tautomers are similar in energy, or even more stable, than their aromatic analogues. In these cases, intramolecular hydrogen bonding and/or dipolar attractive interactions have been employed to rationalize the apparent anomaly. The influence on the stability of structures arising from the delocalization of $\pi$ and lone pair electrons (in the case of six electrons, partial aromaticity) has not been properly addressed and because the spatial magnetic properties of conjugated moieties has proven to be very sensitive to these influences, ${ }^{3,18}$ TSNMRS were computed and appropriately examined herein as the central topic of this paper.

Of significant note though, there have been some recent developments of $\mathrm{NICS}^{24}$ showing that none of the methods can safely assign aromaticity ${ }^{25}$ and non-measurable parameters have proven generally to be unsuitable for quantitative evaluation of aromaticity. ${ }^{26-30}$ There have been some recent developments also of the NICS index ${ }^{31}$ showing that it is not the average NICS, but rather only the NICS $(1)_{\text {zz }}$ component that need be used to quantify aromaticity ${ }^{32}$ within this context and average NICS values have even been proven to be unsuitable generally for the quantitative evaluation of aromaticity. ${ }^{33}$

In addition, the conventional interpretation of deshielded ${ }^{1} \mathrm{H}$ chemical shifts for aromatic protons has proven to be due to reasons other than deshielding ring current effects ${ }^{34}$ and thus they are not reliable indicators of aromaticity as well. ${ }^{35}$ For example, NICS analysis was shown to lead to an incorrect prediction of aromaticity for the cyclopropenyl anion. ${ }^{36}$

Further, there a strong reservations to quantify aromaticity from magnetic data only ${ }^{37}$ because it was found to be a multidimensional characteristic ${ }^{38}$ to be dependent on energetic, geometric and magnetic criteria. ${ }^{39,40}$ In this context, the results of this study will be considered within this multidimensional dependence of aromaticity.

\section{Computational details}

Quantum chemical calculations were performed using the Gaussian 03 program package. ${ }^{41}$ Structures were fully optimized at the MP2/6-311G** level of theory ${ }^{42}$ (the larger molecules 5 to 6 were computed at B3LYP/6-311G** level of theory) considering chloroform as solvent employing the IEFPCM model) and NICS values ${ }^{1}$ were computed for these geometries using the 
GIAO method ${ }^{43}$ at the B3LYP/6-311G** theory level. ${ }^{44}$ To calculate NICS values, ghost atoms were placed on a lattice extending from $-10 \AA$ to $+10 \AA$ with a step size of $0.5 \AA$ in all the three directions of the Cartesian coordinate system and with the zero point of the coordinate system positioned at the centers of the structures. The resulting 68,921 NICS values were analyzed and visualized using SYBYL 7.3 molecular modeling software. ${ }^{45}$

\section{Results and discussion}

Characteristic spatial magnetic properties of benzenoid and quinoid tautomeric structures. Hydroquinone 1 and para-benzoquinone 2 (Scheme 1) serve as prototype benzenoid and quinoid structures, respectively, as can be readily ascertained from the spatial magnetic properties (TSNMRS) of both compounds (see Figure 1). ${ }^{22}$

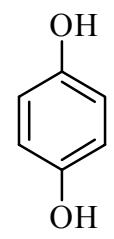

1

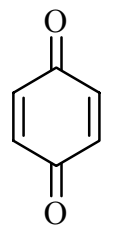

2

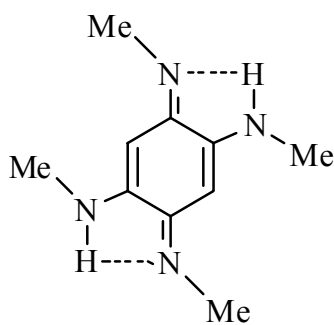

3

\section{Scheme 1}

Whilst hydroquinone 1 shows the characteristic shielding ICSS of benzene ${ }^{3,18}$ above and below the plane of the ring, the deshielding in-plane belt is not closed as in benzene. The reasons for this divergence are the hydroxyl groups in the para positions of the hydroquinone $\mathbf{1}$ which have shielding ICSS in-plane due to the inversed anisotropic effect of the $\mathrm{C}-\mathrm{O}$ single bond. ${ }^{3}$ The spatial magnetic properties of para-benzoquinone $\mathbf{2}$, however, were found to be completely different. $^{22}$ First of all, the TSNMRS values in the lateral view are not dominated by the ring current effects of the aromatic structure as in benzene and hydroquinone 1 , but rather by the anisotropic effects of the conjugated $\mathrm{C}=\mathrm{C}$ and $\mathrm{C}=\mathrm{O}$ double bonds. This is impressively seen for the $\mathrm{C}=\mathrm{C}$ double bonds in the lateral view (top depiction in Figure 1); shielding ICSS are only closed around these $\mathrm{C}=\mathrm{C}$ double bonds. In the center of the para-benzoquinone 2 ring system there is even deshielding of $-0.1 \mathrm{ppm}$ and there is no hint of aromaticity at all. The anisotropic effects of the para-positioned carbonyl groups are best evaluated from the top perspective (lower depiction in Figure 1). They have anisotropic effects of the same direction as aromatic systems with deshielding in-plane and shielding above and below the molecular plane, though similar in size to the $\mathrm{C}=\mathrm{C}$ double bonds, they are however much smaller than the benzene ring system. Here though, the deshielding in-plane belt closes. In addition, the conjugation along the quinoid 
tautomer 2 can best be appreciated from the closed shell TSNMRS in Figure 1. Again, aromaticity at all cannot be found in the center of the six-membered ring and shielding above and below the conjugated moiety is very similar. Perhaps there is greater shielding above the $\mathrm{C}=\mathrm{O}$ and formal $\mathrm{C}=\mathrm{C}$ double bonds, but the shielding above and below the formal $\mathrm{C}-\mathrm{C}$ single bonds is not much different, thereby characterizing excellently the conjugated structure of the quinoid tautomer.

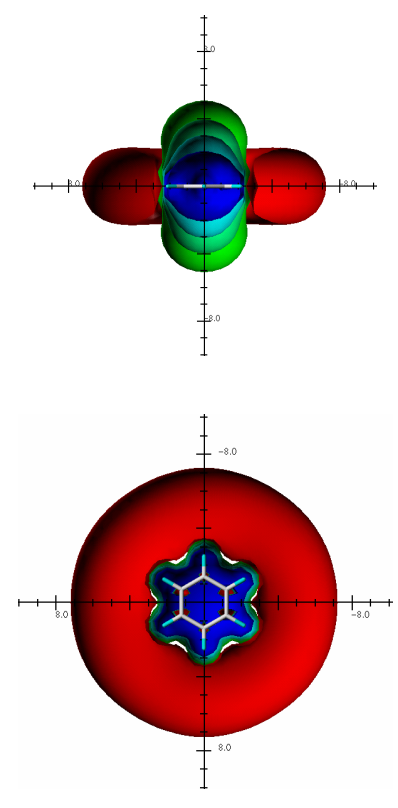

Benzene

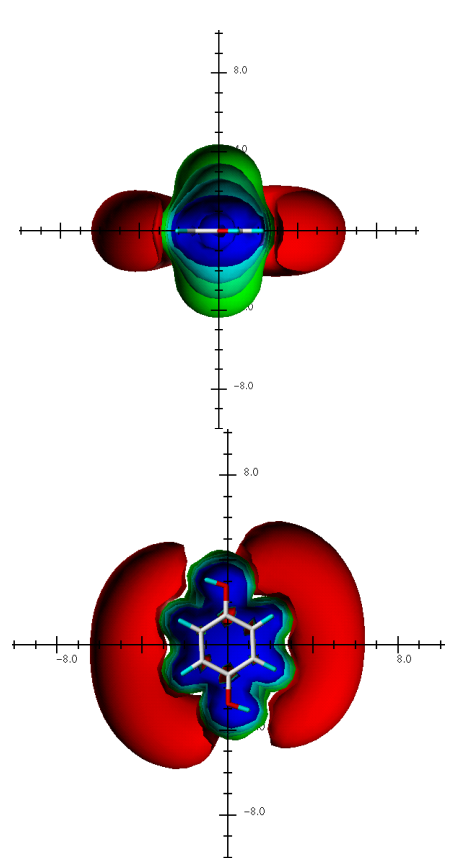

Hydroquinone
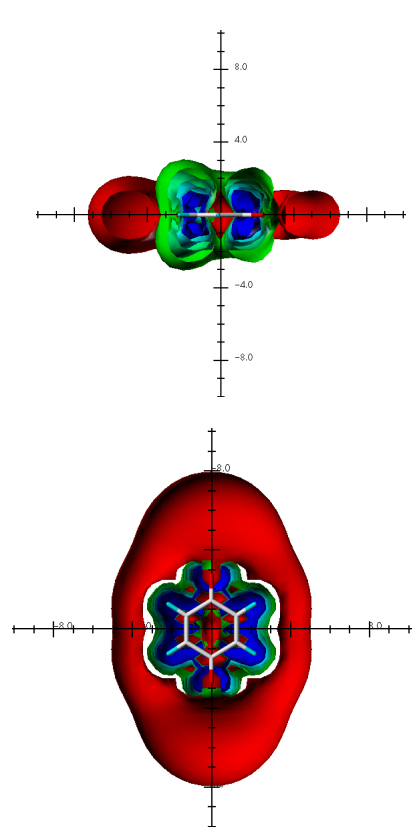

para-Benzoquinone (from different directions)

Figure 1. Visualization of the spatial magnetic properties (TSNMRS) of benzene, 3,18 hydroquinone $^{22}$ and para-benzoquinone ${ }^{22} \mathbf{2}$ as references at various ICSS (blue, -5 ppm shielding; cyan, -2 ppm shielding; greenblue, -1 ppm shielding; green, -0.5 ppm shielding; red, +0.1 ppm deshielding).

Matters do not change principally if the TSNMRS of 2,5-diNHR-substituted parabenzoquinonediimine $\mathbf{3}$ are examined (cf. Figure 2) and compared with the spatial magnetic properties of the iso-electronic para-benzoquinone 2 . The former compound is expected to be potentially antiaromatic ${ }^{46}$ and, due to the special substitution, is estimated from the X-ray structure to consist of two independent $6 \pi$-electron trimethine cyanine subunits ${ }^{47}$ which are connected via two $\mathrm{C}-\mathrm{C}$ single bonds (ca. $1.5 \AA$ in length both from X-ray measurements as well as by DFT calculations). ${ }^{47}$ If the spatial magnetic properties of $\mathbf{3}$ are carefully examined, however, there is noted to be no difference between the TSNMRS of para-benzoquinone 2 and 3. In both cases the conjugated quinoid moiety is described by similar, if not identical, TSNMRS due to the anisotropic effects of the former $\mathrm{C}=\mathrm{C}$ double and $\mathrm{C}-\mathrm{C}$ single bonds which are now 
partially conjugated $\mathrm{C}=\mathrm{C}$ double bonds (cf. Figure 3 ). This can be appreciated even better by the closed ICSS depicted in Figure 2. Thus there is no difference between $\mathbf{2}$ and $\mathbf{3}$ and furthermore there is no indication at all of antiaromaticity (consider for example, as a prototype, cyclobutadiene $)^{3,18}$ and finally, there is no indication from the spatial magnetic properties of independent $6 \pi$-electron trimethine cyanine subunits ${ }^{47}$ in $\mathbf{3}$. Obviously, even for bond lengths of $1.5 \AA$, approximately equivalent to pure $\mathrm{C}-\mathrm{C}$ single bonds, the spatial magnetic properties prove substantial anisotropic substituent effects of the conjugated partial $\mathrm{C}=\mathrm{C}$ double bonds and no indication of $\mathrm{C}-\mathrm{C}$ single bonds at all (for a difference, compare, for example, hydroquinone $\mathbf{1}$ in Figure 1). It seems that the discussion of X-ray bond lengths in the context of single, partial double and double bonds with respect to conjugation in the delocalized $\pi$-electron/lone pair systems should be complemented by the spatial magnetic properties of the systems in order to thoroughly understand the electronic state of conjugated $\pi$ systems.
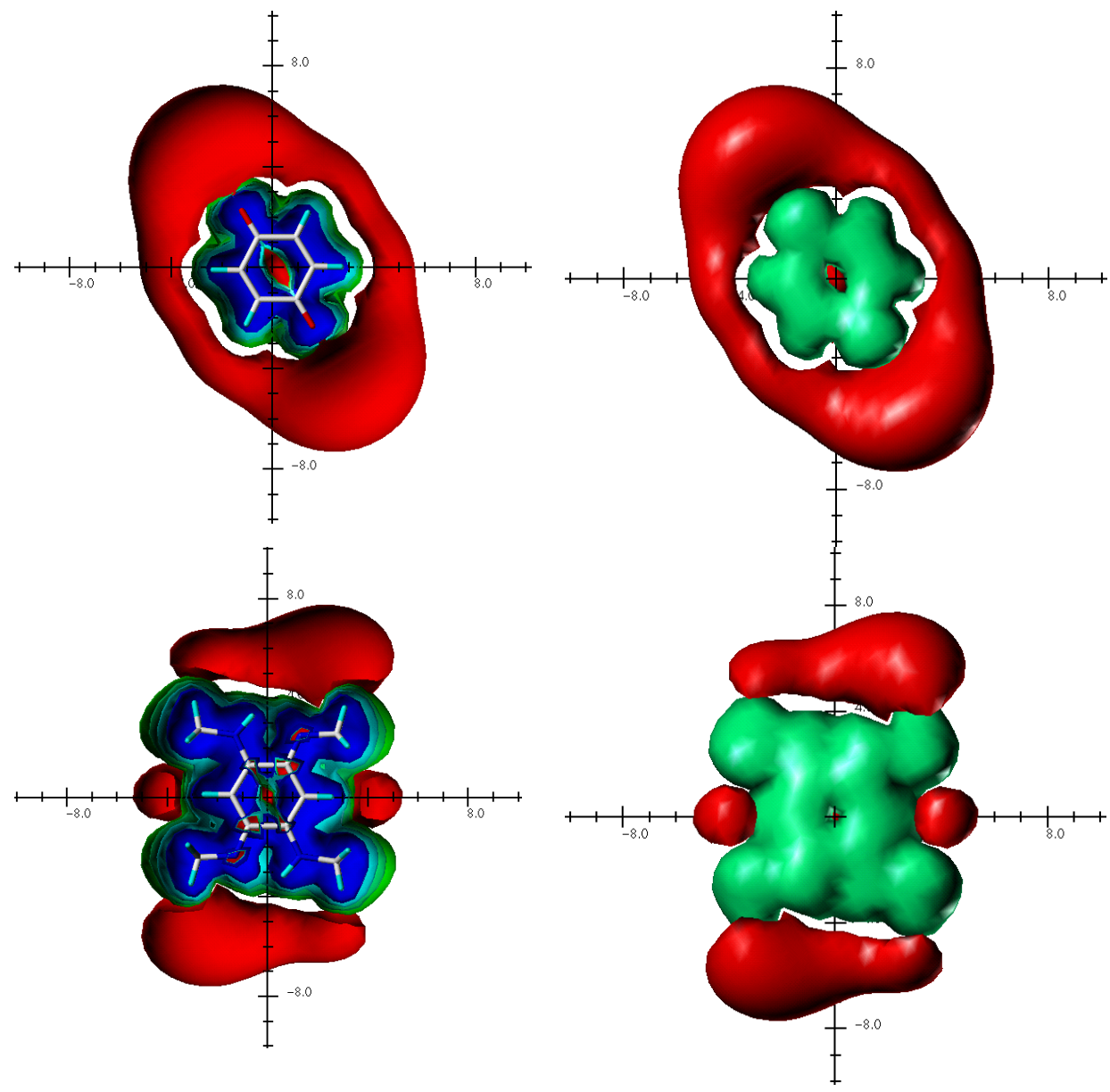

Figure 2. Visualization of the spatial magnetic properties (TSNMRS) of para-benzoquinone 2 (above) and 2,5-di-NHMe-substituted benzoquinonediimine 3 (below) at various ICSS (blue, -5 ppm shielding; cyan, -2 ppm shielding; greenblue, -1 ppm shielding; green, -0.5 ppm shielding; red, +0.1 ppm deshielding). 
The TSNMRS of $\mathbf{3}$ without hydrogen bonding have also been calculated (cf. Figure 3, right structure) and from which it was found that the spatial magnetic properties of this structure do not alter significanlty. Therefore the two main sources for the stability of keto-enol tautomers operate independently but, as expected, the molecule is less stable by $18.02 \mathrm{kcal} \mathrm{mol}^{-1}$.

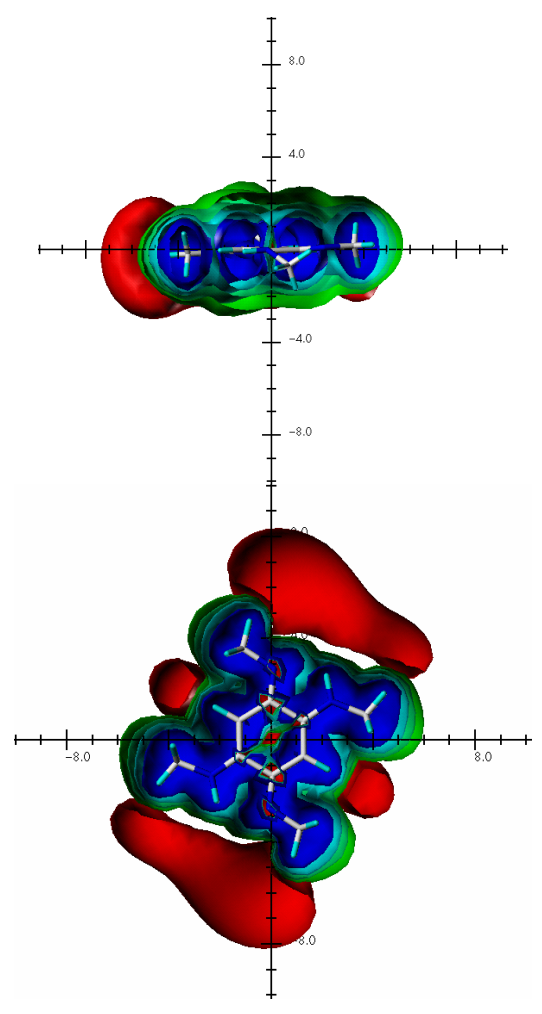

3 (from different directions)

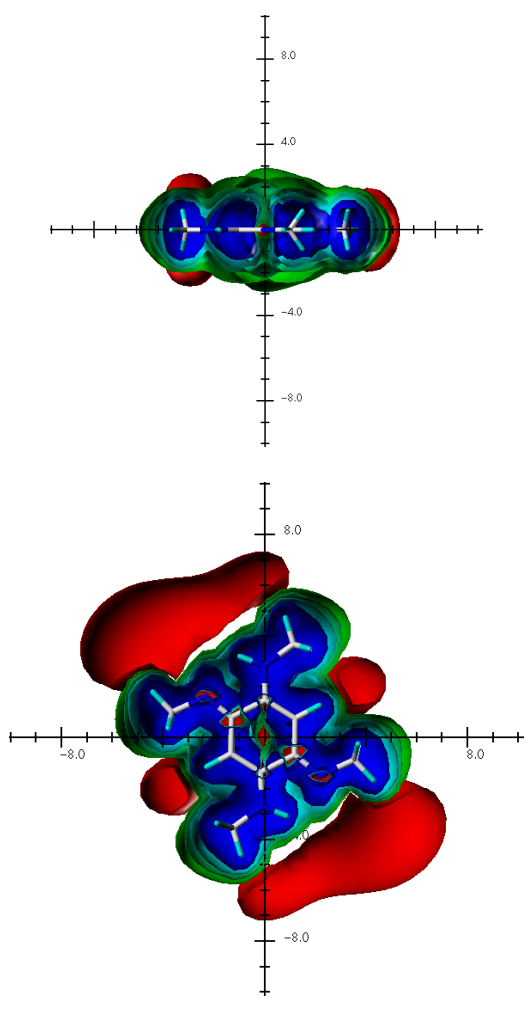

3 (without $\mathrm{N}-\mathrm{H} . . . \mathrm{N}=\mathrm{H}-\mathrm{bond}$ )

Figure 3. Visualization of the spatial magnetic properties (TSNMRS) of 2,5-di-NHMesubstituted benzoquinonediimine 3 with (left) and without (right) hydrogen bonding at various ICSS (blue, -5 ppm shielding; cyan, -2 ppm shielding; greenblue, -1 ppm shielding; green, -0.5 ppm shielding; red, +0.1 ppm deshielding).

Due to aromaticity, benzenoid structures are more stable than quinoid structures and, as just seen, both structures have characteristically different spatial magnetic properties (TSNMRS). With this knowledge in hand, we can now move to the quinoid structures which are similar in stability, or even more stable, than their corresponding benzenoid tautomers and will use the corresponding TSNMRS to visualize the ring current and anisotropic effects in these compounds by ICSS and hence try to quantify the inherent aromaticity or the degree of delocalization of the $\pi$ electrons and lone pair electrons as the source of their stability. 
Spatial magnetic properties of keto-enol tautomers of benzodifurantrione. In the solid state, benzodifurantrione 4 (Scheme 2) prefers the quinoid enol tautomer $4 \mathbf{b} .^{48}$ In solution two tautomers, including the keto form $\mathbf{4 a}$ in addition to the isolated phenylogous enol tautomer $\mathbf{4 b}$, were observed in several solvents and which were readily assigned by ${ }^{1} \mathrm{H}$ and ${ }^{13} \mathrm{C} N M R$ spectroscopy. ${ }^{48}$ Of note, different, but comparable, keto-enol ratios were observed in the various solvents. $^{48}$

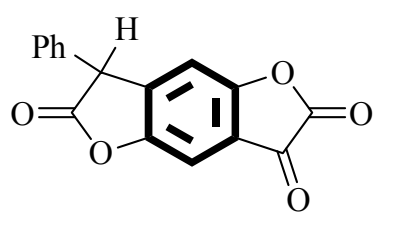

$4 a$

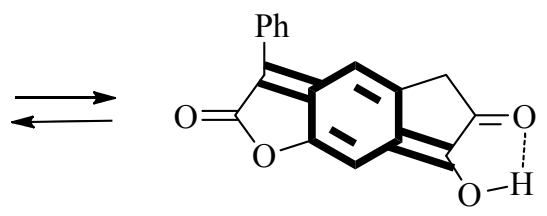

4b

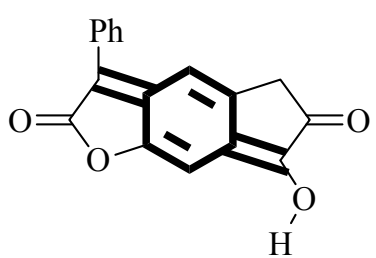

$4 \mathrm{c}$

\section{Scheme 2}

Both the structures and TSNMRS of the two tautomers were calculated by ab initio MO methods and are depicted in Figure 4. In the visualization of the spatial magnetic properties of the two tautomers, the major difference between the two tautomers is clearly evident: The benzenoid central ring in $\mathbf{4 a}$ is shown to be aromatic (ICSS of $-0.5 \mathrm{ppm}$ at $4.5 \AA$ and $-1 \mathrm{ppm}$ at $3.4 \AA$; for benzene: ICSS of $-0.5 \mathrm{ppm}$ at $5.2 \AA$ and $-1 \mathrm{ppm}$ at $4.0 \AA$ ) whilst the TSNMRS above and below the central ring in $\mathbf{4 b}$ drop to ICSS values of $-0.5 \mathrm{ppm}$ at $3.0 \AA$ and $-1 \mathrm{ppm}$ at $2.3 \AA$ due to the quinoid character of the central ring of this tautomer. The two furan moieties at the aromatic central ring in $\mathbf{4 a}$ are not conjugated and red dots in their centers are an indication of the anisotropic effects of the isolated carbonyl groups only.

On the other hand, in the quinoid tautomer $\mathbf{4 b}$, the two furan rings are conjugated to the central ring and thus the conjugation extends over the whole system (ICSS of $-0.5 \mathrm{ppm}$ at $2.9 \AA$ and $-1 \mathrm{ppm}$ at $2.1 \AA$ above and below the centers of the furan ring moieties). In addition, the phenyl substituent at C-3 is also included in the conjugation. Obviously, the diminished aromaticity of the central ring in $\mathbf{4 b}$ compared with $\mathbf{4 a}$ is essentially balanced in $\mathbf{4 b}$ by distinctive $\pi$ delocalization in the extended, conjugated annulated ring system of $\mathbf{4 b}$. In addition, intramolecular hydrogen bonding was calculated to improve the stability of $\mathbf{4 b}$ in comparison with $4 \mathrm{c}$ (cf. Scheme 2) by $3.86 \mathrm{kcal} \mathrm{mol}^{-1}$, but it is of negligible influence on the $\pi$-electron delocalization (cf. Figure 4). This is indicated by the common shell of TSNMRS of rather constant and extended size over the entire conjugated system (ICSS of $-0.5 \mathrm{ppm}$ at $4.0-3.2 \AA$ and -1 ppm at 3.3-2.4 $\AA$ ). Thus, TSNMRS not only help to identify aromaticity, but also to visualize the size of the extended conjugation in such systems as well.

In consideration of the results so far, it can be ascertained that comparable stability of nonaromatic, quinoid tautomers results from remarkable extended $\pi$ conjugation $^{49}$ and intramolecular hydrogen bonding. On the other hand, both effects operate independently-the spatial magnetic properties of the enol form $\mathbf{4 b}$ do not change without the intramolecular 
hydrogen bonding in $\mathbf{4 c}$ (Figure 4) which is of substantial magnitude with respect to the stability of this tautomer. In this case, at least, the consideration of aromaticity in the light of spatial magnetic properties only remains insufficient for quantifying the stabilization of aromatic structures when comparing the latter with non-aromatic but strongly stabilized quinoid tautomers. $^{37-40}$
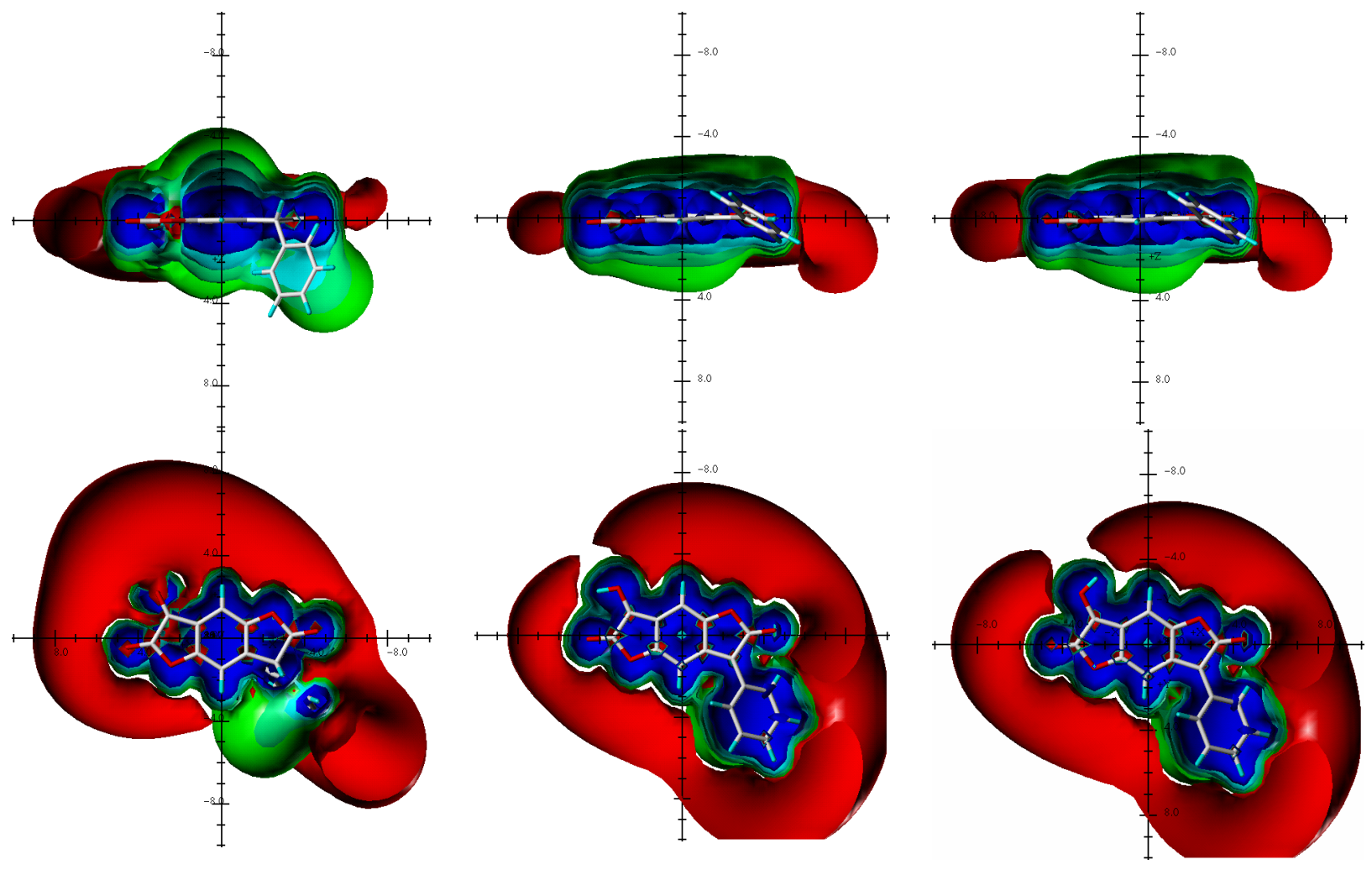

Figure 4. Visualization of the spatial magnetic properties (TSNMRS) of benzodifurantrione 4 [4a keto form (left), $\mathbf{4 b}$ enol form (middle), $\mathbf{4 c}$ enol form without hydrogen bonding (right)] at various ICSS (blue, -5 ppm shielding; cyan, -2 ppm shielding; greenblue, -1 ppm shielding; green, -0.5 ppm shielding; red, +0.1 ppm deshielding).

Spatial magnetic properties of keto-enol tautomers of $\alpha, \beta, \beta$-disubstituted phenazines and bridged bisphenazine analogs. In the keto-enol equilibrium of the bridged bisphenazines 5a and 5b (Scheme 3), the nonaromatic quinoid keto form was found to be the predominant tautomer both in the solid state as well as in solution. ${ }^{50}$ DFT calculations confirmed quinoid structure $\mathbf{5 b}$ to be the more stable by $4.2 \mathrm{kcal} \mathrm{mol}^{-1}$ in comparison with $\mathbf{5 a}$ and the key roles of the NH- $n$ Pr substituents were as H-donor substituents for two additional hydrogen bonds ${ }^{50}$ (amounting to $10.6 \mathrm{kcal} \mathrm{mol}^{-1}$ ). Because this kind of hydrogen bonding in quasi-five-membered rings is not very stabilizing ${ }^{51}$ [in $\mathbf{5 b}: r(\mathrm{NH} . . \mathrm{O}=\mathrm{C}), 2.21$ and $2.26 \AA ; \delta(\mathrm{NH}), 6.34 \mathrm{ppm}$ ], ${ }^{50}$ the influence on the stability of $5 \mathbf{a}$ and $5 \mathbf{b}$ and also the monomers $6 \mathbf{a}$ and $\mathbf{6 b}$ (6c was studied to measure the stability of the hydrogen bond; cf. Scheme 3) due to the delocalization of $\pi$ electrons 
and lone pairs was examined by calculation of their spatial magnetic properties (TSNMRS) and appropriate visualization as ICSS of different size and direction.

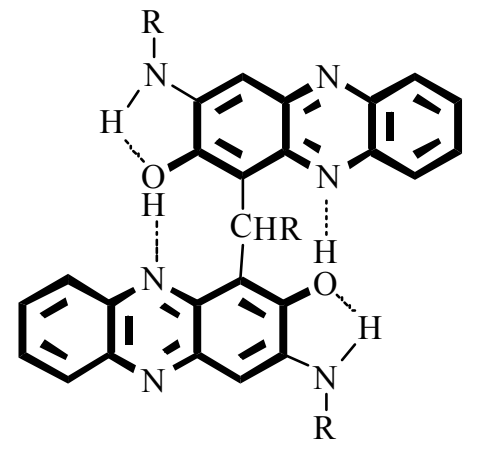

$5 \mathbf{a}$

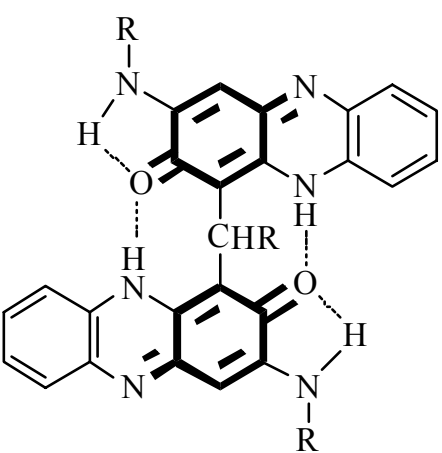

5b<smiles>[R]N1[TlH]Oc2c1cc1nc3ccccc3nc1c2C</smiles>

6a<smiles></smiles>

6b<smiles>[R]Nc1cc2nc3ccccc3[nH]c-2c(C)c1=O</smiles>

6c

\section{Scheme 3}

The keto tautomer $\mathbf{6 b}$, as was found for $\mathbf{5 b}$ in the dimer, proved to be more stable by 4.16 kcal $\mathrm{mol}^{-1}$ in $\mathrm{CDCl}_{3}$ than the enol form 6a. Comparison of the TSNMRS values of the two tautomers 6a and $\mathbf{6 b}$ (visualized in Figure 5) resulted in the following observations: Partial aromaticity ( $\pi$ conjugation) above and below the trisubstituted ring of the phenazine moiety drops as indicated by ICSS of $-0.5 \mathrm{ppm}$ at $5.9 \AA$ and $-1.0 \mathrm{ppm}$ at $4.1 \AA$ in $\mathbf{5 a}$ in comparison to ICSS of $-0.5 \mathrm{ppm}$ at $4.9 \AA$ and $-1.0 \mathrm{ppm}$ at $3.5 \AA$ in $\mathbf{6 b}$ to demonstrate appropriately the reduced partial aromaticity in this part of the molecule. Thus the stability of $\mathbf{6 b}$ declines due to adequately reduced $\pi$ conjugation but is still $4.16 \mathrm{kcal} \mathrm{mol}^{-1}$ more stable than 6a. The stabilization gain must come from intramolecular hydrogen bonding because the keto tautomer of structure $6 \mathrm{c}$ is less stable by $7.6 \mathrm{kcal} \mathrm{mol}^{-1}$, thus the intramolecular hydrogen bonding must be balancing more than sufficiently the energy shortcoming in the $\pi$ conjugation. The TSNMRS in $\mathbf{6 c}$ in comparison with $\mathbf{6 b}$ are unchanged (cf. Figure 5).

The same $\pi$ conjugation conditions could be expected for dimers $5 \mathbf{a}$ and $\mathbf{b}$ because the monomers are connected via the $\mathrm{sp}^{3}$ carbon atom link only and nothing has changed with respect to tautomerism. Thus, an considerably, by at least $8.31 \mathrm{kcal} \mathrm{mol}^{-1}$ in magnitude, more stable diketo tautomer $\mathbf{5 b}$ could be expected with the additional stabilization energy coming from the two new intramolecular hydrogen bonds $\mathrm{N}-\mathrm{H}$... $\mathrm{O}=\mathrm{C}$ between the monomer units. But since, in principal, the two new $\mathrm{O}-\mathrm{H} . .-\mathrm{N}=$ hydrogen bonds in 5a could stabilize this tautomer as well, the 
$\pi$ delocalization (partial aromaticity) of the trisubstituted ring phenazine moieties in both tautomers 5a and 5b was evaluated. The TSNMRS of 5a and $\mathbf{5 b}$ are visualized in Figure 6 and ICSS values, together with the former values for $\mathbf{5} \mathbf{a}$ and $\mathbf{5} \mathbf{b}$, are presented in Table 1.
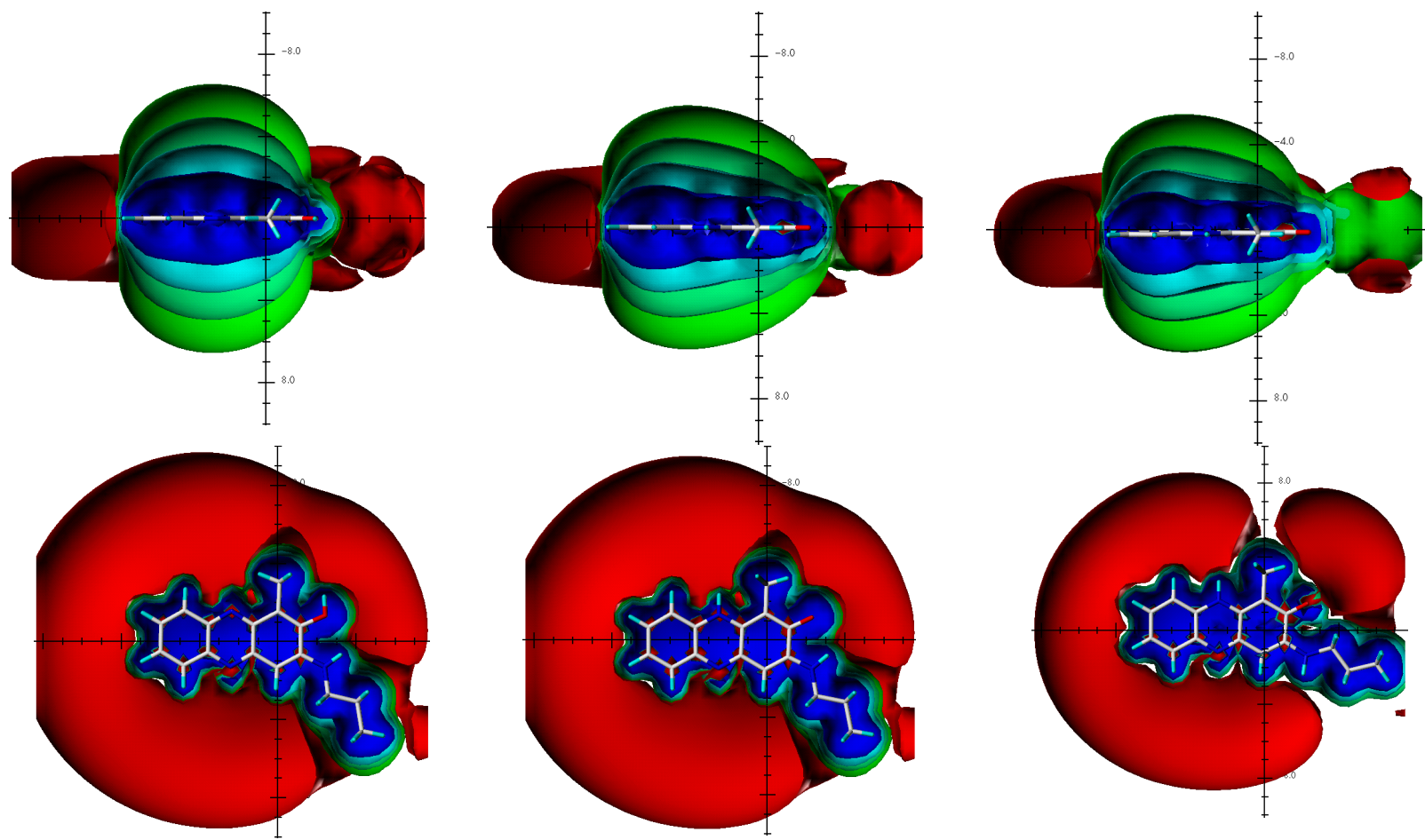

Figure 5. Visualization of the spatial magnetic properties (TSNMRS) of $\alpha \beta \beta$-tris-substituted phenazine tautomers 6 [6a enol form (left), b keto form (middle), $\mathbf{6 c}$ keto form without hydrogen bonding (right)] at various ICSS (blue, -5 ppm shielding; cyan, -2 ppm shielding; greenblue, -1 ppm shielding; green, -0.5 ppm shielding; red, +0.1 ppm deshielding).

It immediately garners the attention that, compared with the difference between $\mathbf{6 a}$ and $\mathbf{6 b}, \pi$ delocalization drops in the keto tautomer $\mathbf{5 b}$ with respect to $\mathbf{5 a}$, though not so dramatically. Actually, the difference in $\pi$ delocalization is lower, indicating for $\mathbf{5 b}$ smaller, but not much different, stabilization due to the conjugation of the $\pi$ electrons and lone pairs in the trisubstituted phenyl moieties in both tautomers. In the remainder of the molecules (nonsubstituted phenyl and central pyrazine moieties), there is not much difference anyway (cf. Figure 6) and compared with the monomeric tautomeric structures, in terms of ICSS, the $\pi$ conjugation in $\mathbf{6} \mathbf{b}$ is much better than in 5b and even identical to $\mathbf{6 a}$, the so-called "aromatic" tautomer. Thus, the additional hydrogen bonds between the monomer moieties $[\delta(\mathrm{NH}), 14.84 \text { and } 15.78 \mathrm{ppm}]^{50}$ must have significant influences on the stability of the predominant tautomer $\mathbf{5 b}$. 

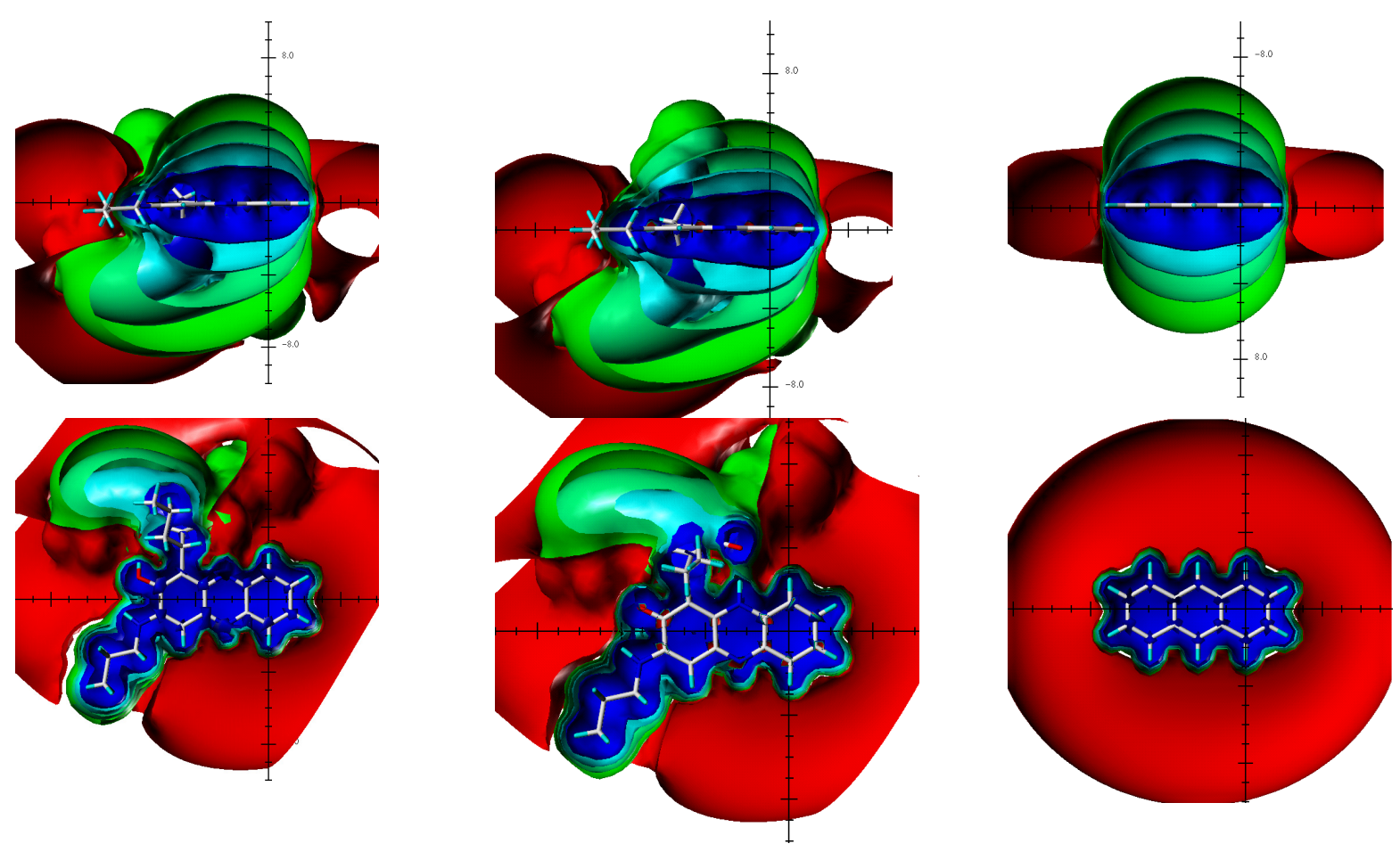

Figure 6. Visualization of the spatial magnetic properties (TSNMRS) of dimers of phenazine tautomers 5 [5a enol form (left), b keto form (middle)] and of anthracene (right) at various ICSS (blue, -5 ppm shielding; cyan, -2 ppm shielding; greenblue, -1 ppm shielding; green, -0.5 ppm shielding; red, +0.1 ppm deshielding).

Table 1. Stability of the tautomers $5 \mathbf{a}, \mathbf{5 b}$ and $\mathbf{6} \mathbf{a}-\mathbf{c}$ and TSNMRS ${ }^{3,18}$ at ICSS above and below the center of the trisubstituted phenyl moiety of the phenazine structure

\begin{tabular}{|c|c|c|c|c|}
\hline \multirow{2}{*}{\multicolumn{2}{|c|}{ No. Solvent }} & \multirow[t]{2}{*}{ Relative energy $\left[\mathrm{kcal} \mathrm{mol}^{-1}\right]$} & \multicolumn{2}{|c|}{ ICSS $[\AA]$} \\
\hline & & & at $-0.5 \mathrm{ppm}$ & at $-1.0 \mathrm{ppm}$ \\
\hline \multirow[t]{2}{*}{$5 \mathbf{a}$} & DMSO & 5.24 & 4.9 & 3.5 \\
\hline & $\mathrm{CHCl}_{3}$ & 5.11 & - & - \\
\hline \multirow[t]{2}{*}{$5 \mathbf{b}$} & DMSO & 0.00 & 4.5 & 3.2 \\
\hline & $\mathrm{CHCl}_{3}$ & 0.00 & - & - \\
\hline \multirow[t]{2}{*}{$6 \mathbf{a}$} & DMSO & 4.57 & 5.9 & 4.1 \\
\hline & $\mathrm{CHCl}_{3}$ & 4.16 & 5.9 & 4.2 \\
\hline \multirow[t]{2}{*}{$6 b$} & DMSO & 0.00 & 5.0 & 3.5 \\
\hline & $\mathrm{CHCl}_{3}$ & 0.00 & 4.9 & 3.5 \\
\hline & $\mathrm{CHCl}_{3}$ & 7.60 & - & - \\
\hline \multicolumn{2}{|c|}{ Anthracene ${ }^{3,18}$} & - & 6.2 & 4.5 \\
\hline
\end{tabular}


However, there are two possible solutions. From the expected stability difference between 5b and 5a (8-9 kcal mol ${ }^{-1}$ due to doubled monomer differences), only ca. $5 \mathrm{kcal} \mathrm{mol}^{-1}$ are verifiable which means that the additional $\mathrm{O}-\mathrm{H} . . .-\mathrm{N}=$ hydrogen bonding in 5a is more profitable than the $\mathrm{N}-\mathrm{H} . . . \mathrm{O}=\mathrm{C}$ hydrogen bonds in $\mathbf{5 b}$. But at the same time, as indicated by TSNMRS, conjugation of the $\pi$ electrons and lone pairs in $\mathbf{5 b}$ is not much less than in 5a. Thus, intramolecular $\mathrm{N}-\mathrm{H} . . . \mathrm{O}=\mathrm{C}$ hydrogen bonding in both $\mathbf{5 b}$ and $\mathbf{6 b}$ and accelerated $\pi$ conjugation in 5b due to intramolecular $\mathrm{N}-\mathrm{H} . . . \mathrm{O}=\mathrm{C}$ hydrogen bonding between the monomer units stabilize this tautomer sufficiently for it to be dominant in both the solid state as well as in solution. ${ }^{50}$

Another quite interesting aspect is the comparison of the aromaticity in the enol tautomers $5 \mathbf{a}$ and $\mathbf{6 a}$ with the aromaticity of the terminal rings in anthracene (cf. Figure 6 and Table 1). Employing our approach, ${ }^{18}$ the corresponding TSNMRS above and below the terminal ring of anthracene and the trisubstituted phenyl moieties of the enol tautomers in 5a and $\mathbf{6 a}$ indicate that the difference is not too significant for $6 \mathbf{a}$ (for $\mathbf{6 a}$ : ICSS of $-0.5 \mathrm{ppm}$ at $5.9 \AA$ and -1 ppm at 4.2 $\AA$; for anthracene: ICSS of $-0.5 \mathrm{ppm}$ at $6.2 \AA$ and $-1 \mathrm{ppm}$ at $4.5 \AA$ ). The aromaticity of the $\pi$ deficient aromatic phenazine is lower than in anthracene in complete agreement with the conventionally taught doctrine of organic chemistry. However, when applying the same standard to 5a, the difference is quite remarkable. For 5a, ICSS of $-0.5 \mathrm{ppm}$ at $4.9 \AA$ and $-1 \mathrm{ppm}$ at $3.5 \AA$ indicate that partial aromaticity in the enol tautomer 5a is still present. However, it is much smaller than in anthracene and this only changes slightly when comparison to the corresponding keto tautomer $\mathbf{5 b}$ is made (ICSS of $-0.5 \mathrm{ppm}$ at $4.5 \AA$ and $-1 \mathrm{ppm}$ at $3.2 \AA$ ). Thus arises the general question that, if in these cases, should one continue to talk about partial aromaticity in the enol and conjugation of $\pi$ electrons and lone pairs in the corresponding "nonaromatic" keto tautomer, or only consider the degree of conjugation of $\pi$ electrons and lone pairs in both tautomers. The latter approach is deemed to be the better choice because, obviously, to quantify the stabilizing effect of aromaticity from spatial magnetic properties as single criterion on the stability of substances remains unsufficient. ${ }^{37-40}$

Obviously, by the assessment of tautomerism with respect to both aromaticity and hydrogen bonding as stabilizing factors, the indication seems to be that one should not be constrained by the corresponding stabilities regarding only the aromaticity present in one of the tautomers. For example, the corresponding quinoid keto analogs are stabilized by $\pi$ electron and lone pair conjugation as well. Thus, to evaluate the different influences on tautomer stability, TSNMRS of the conjugated moieties in both tautomers are able to provide useful information. 


\section{Conclusions}

A new approach has been introduced to assess the stability of quinoid and benzenoid keto-enol tautomeric structures on the basis of through-space NMR shieldings (TSNMRS). The usually more stable benzenoid tautomers can be evaluated using TSNMRS (visualized by ICSS of different size and direction) on the basis of ring current effects and the usually less stable quinoid tautomers on the basis of the anisotropic effects of $\pi$ conjugation. In cases of similar stability for the two tautomers (normally arising due to additional intramolecular hydrogen bonding), the conventional designation of aromatic and nonaromatic tautomers can be retained. However, in addition to differences in stability due to hydrogen bonding, differing stability also arises from $\pi$ electron and lone pair delocalization.

\section{Acknowledgement}

Dr. Karel D. Klika is thanked for language correction of the manuscript.

\section{References}

1. Chen, Z.; Wannere, C. S.; Corminboeuf, C.; Puchta, R.; Schleyer, P. v. R. Chem. Rev. 2005, 105,3842 .

2. Schleyer, P. v. R.; Manoharan, M.; Wang, Z. X.; Kiran, B.; Jiao, Y.; Puchta, R.; von E. Hommes, N. J. R. Org. Lett. 2001, 3, 2465.

3. Klod, S.; Kleinpeter, E. J. Chem. Soc., Perkin Trans. 2 2001, 1893.

4. Merino, G.; Heine, T.; Seifert, G. Chem.-Eur. J. 2004, 10, 4367.

5. Merino, G.; Vela, A.; Heine, T. Chem. Rev., 2005, 105, 3812.

6. Facelli, J.C. Magnet. Res. Chem. 2006, 44, 401.

7. Heine, T. Islas, R.; Merino, G. J. Comp. Chem. 2007, 28, 302.

8. Viglione, R. G.; Zanasi, R.; Lazzeretti, P. Org. Lett. 2004, 6, 2265.

9. Kleinpeter, E.; Klod, S.; Rudorf, W.-D. J. Org. Chem. 2004, 69, 4317.

10. Kleinpeter, E.; Klod, S. J. Am. Chem. Soc. 2004, 126, 2231.

11. Ryppa, C.; Senge, M. O.; Hatscher, S. S.; Kleinpeter, E.; Wacker, Ph.; Schilde, U.; Wiehe, A. Chem.-Eur. J. 2005, 11, 3427.

12. Kleinpeter, E.; Schulenburg, A.; Zug, I.; Hartmann, H. J. Org. Chem. 2005, 70, 6592.

13. Kleinpeter, E.; Schulenburg, A. J. Org. Chem. 2006, 71, 3869.

14. Kleinpeter, E.; Koch, A.; Sahoo, H. S.; Chand, D. K. Tetrahedron 2008, 64, 5044.

15. Kleinpeter, E.; Lämmermann, A.; Kühn, H. Org. Biomol. Chem. 2011, 9, 1098.

16. Kleinpeter, E.; Koch, A.; Seidl, P. R. J. Phys. Chem. A 2008, 112, 4989. 
17. Kleinpeter, E.; Szatmári, I.; Lázár, L.; Koch, A.; Heydenreich, M.; Fülöp, F. Tetrahedron 2009, 65, 8021.

18. Kleinpeter, E.; Klod, S.; Koch, A. J. Mol. Struct. (THEOCHEM) 2007, 811, 45 and references cited therein.

19. Kleinpeter, E.; Koch, A. J. Mol. Struct. (THEOCHEM) 2008, 851, 313.

20. Kleinpeter, E.; Klod, S.; Koch, A. J. Org. Chem. 2008, 73, 1498.

21. Kleinpeter, E.; Koch, A. J. Mol. Struct. (THEOCHEM) 2010, 939, 1.

22. Kleinpeter, E.; Koch, A. J. Phys. Chem. A 2010, 114, 5928.

23. Kleinpeter, E.; Bölke, U.; Koch, A. J. Phys. Chem. A 2010, 114, 7616.

24. Fallah-Bagher-Shaidaei, H.; Wannere, C. S.; Corimboeuf, C.; Schleyer, P. v. R. Org. Lett. 2006, 5, 683 .

25. Stanger, A. Chem.-Eur. J. 2006, 12, 2745.

26. Lazzeretti, P. Phys. Chem. Chem. Phys. 2004, 6, 217.

27. Osuna, S.; Poater, J.; Bofill, J. M.; Alemany, P.; Sola, M. Chem. Phys. Lett. 2006, 428, 191.

28. Feixas, F.; Matito, E.; Poater, J.; Sola, M. J. Phys. Chem. A 2007, 111, 4513.

29. Islas, R.; Martinez-Guajardo, G.; Jimenez-Halla, J. O. C.; Sola, M.; Merino, G. J. Chem. Theory Comput. 2010, 6, 1131.

30. Castro, A. C.; Osorio, E.; Jimenez-Halla, J. O. C.; Matito, E.; Tiznado, W.; Merino, G. J. Chem. Theory Comp. 2010, 6, 2701.

31. (a) Fallah-Bagher-Shaidaei, H.; Wannere, C. S.; Corminboeuf, C.; Puchta, R.; Schleyer, P. v. R. Org. Lett. 2006, 8, 863; (b) Corminboeuf, C.; Heine, T.; Seifert, G.; Schleyer, P. v. R.; Weber, J. Phys. Chem. Chem. Phys. 2004, 6, 273.

32. Stanger, A. Chem.-Eur. J. 2006, 12, 2745.

33. (a) Lazzeretti, P. Phys. Chem. Chem. Phys. 2004, 6, 217; (b) Pelloni, St.; Lazzeretti, P.; Zanasi, R. J. Phys. Chem. A 2007, 111, 8163; (c) Stanger, A. Chem. Commun. 2009, 1939.

34. (a) Wannere, C. S.; Schleyer, P. v. R. Org. Lett. 2003, 5, 605; (b) Viglione, R. G.; Zanasi, R.; Lazzeretti, Org. Lett. 2004, 6, 2265.

35. (a) Wannere, C. S.; Corimboeuf, C.; Allen, W. A.; Schaefer III, H. F.; Schleyer, P. v. R. Org. Lett. 2005, 7, 1457; (b) Faglioni, F.; Ligabue, A.; Pelloni, S.; Soncini, A.; Viglione, R. G.; Ferraro, M. B.; Zanasi, R.; Lazzeretti, P. Org. Lett. 2004, 7, 3457.

36. Martin, N. H.; Loveless, D. M.; Main, K. L.; Wade, D. C. J. Mol. Graph. Model. 2006, 25, 389.

37. Katritzky, A. R.; Jug, K.; Oniciu, D. C. Chem. Rev. 2001, 101, 1421.

38. Katritzky, A. R.; Karelson, M.; Sild, S.; Krygowski, T. M.; Jug, K. J. Org. Chem. 1998, 63, 5228.

39. Katritzky, A. R.; Barczynski, P.; Musumarra, G.; Pisano, D.; Szafran, M. J. Am. Chem. Soc. 1989, $111,7$.

40. Jug, K.; Köster, A. M. J. Phys. Org. Chem. 1991, 4, 163.

41. Frisch, M. J.; Trucks, G. W.; Schlegel, H. B.; Scuseria, G. E.; Robb, M. A.; Cheeseman, J. R.; Montgomery, J. A., Jr.; Vreven, T.; Kudin, K. N.; Burant, J. C.; Millam, J. M.; Iyengar, 
S. S.; Tomasi, J.; Barone, V.; Mennucci, B.; Cossi, M.; Scalmani, G.; Rega, N.; Petersson, G. A.; Nakatsuji, H.; Hada, B.; Ehara, M.; Toyota, K.; Fukuda, R.; Hasegawa, J.; Ishida, M.; Nakajima, T.; Honda, Y.; Kitao, O.; Nakai, H.; Klene, M.; Li, X.; Knox, J. E.; Hratchian, H. P.; Cross, J. B.; Adamo, C.; Jaramillo, J.; Gomperts, R.; Stratmann, R. E.; Yazyev, O.; Austin, A. J.; Cammi, R.; Pomelli, C.; Ochterski, J. W.; Ayala, P. Y.; Morokuma, K.; Voth, G. A.; Salvador, P.; Dannenberg, J. J.; Zakrzewski, V. G.; Dapprich, S.; Daniels, A. D.; Strain, M. C.; Farkas, O.; Malick, D. K.; Rabuck, A. D.; Raghavachari, K.; Foresman, J. B.; Ortiz, J. V.; Cui, Q.; Baboul, A. G.; Clifford, S.; Cioslowski, J.; Stefanov, B. B.; Liu, G.; Liashenko, A.; Piskorz, P.; Komaromi, I.; Martin, R. L.; Fox, D. J.; Keith, T.; Al-Laham, M. A.; Peng, C. Y.; Nanayakkara, A.; Challacombe, M.; Gill, P. M. W.; Johnson, B.; Chen, W.; Wong, M. W.; Gonzalez, C.; Pople, J. A. Gaussian 03, revision C.02; Gaussian, Inc.: Pittsburgh, PA, 2004.

42. Møller, C.; Plesset, M. S. Phys. Rev. 1934, 46, 618.

43. Ditchfield, R. Mol. Phys. 1974, 27, 789.

44. The lattice points ("ghost atoms") should be sensor points only without energy contributions to the calculations. Only if DFT or HF calculations are applied is this true; in the case of electron correlation calculations, the "ghost atoms" get their own electron density and show some influence on the energy of the system. In these cases, the TSNMRS surfaces are heavily distorted.

45. SYBYL 7.3 Tripos Inc. 1699 South Hanley Road, St. Louis, Missouri 63144, USA (2007).

46. Siri, O.; Braunstein, P. Chem. Commun. 2000, 2223.

47. Siri, O.; Braunstein, P.; Rohmer, M.-M., Bénard, M.; Welter, R. J. Am. Chem. Soc. 2003, $125,13793$.

48. Lawrence, A. J.; Hutchings, M. G.; Kennedy, A. R.; McDouall, J. J. W. J. Org. Chem. 2010, 75,690 .

49. Sarodnick, G.; Linker, T.; Heydenreich, M.; Koch, A.; Starke, I.; Fürstenberg, S.; Kleinpeter, E. J. Org. Chem. 2009, 74, 1282.

50. Seillan, C.; Marsal, Ph.; Siri, O. Org. Biomol. Chem. 2010, 8, 3882.

51. Anslyn, E. V.; Dougherty, D. A. Modern Physical Organic Chemistry, University Sience Books, Saisalito, California, 2006. 